\title{
The Cardiovascular Health in Ambulatory Care Research Team performance indicators for the primary prevention of cardiovascular disease: a modified Delphi panel study
}

\author{
Jack V. Tu MD PhD, Laura C. Maclagan MSc, Dennis T. Ko MD MSc, Clare L. Atzema MD MSc, \\ Gillian L. Booth MD MSc, Sharon Johnston MD LLM, Karen Tu MD MSc, Douglas S. Lee MD PhD, \\ Arlene Bierman MD MS, Ruth Hall PhD, R. Sacha Bhatia MD MBA, Andrea S. Gershon MD MSc, \\ Sheldon W. Tobe MD MSc, Claudia Sanmartin PhD, Peter Liu MD, Anna Chu MHSc; for the \\ CANHEART Primary Prevention Indicator Expert Panel
}

\section{Abstract}

Background: High-quality ambulatory care can reduce cardiovascular disease risk, but important gaps exist in the provision of cardiovascular preventive care. We sought to develop a set of key performance indicators that can be used to measure and improve cardiovascular care in the primary care setting.

Methods: As part of the Cardiovascular Health in Ambulatory Care Research Team initiative, we established a 14-member multidisciplinary expert panel to develop a set of indicators for measuring primary prevention performance in ambulatory cardiovascular care. We used a 2-stage modified Delphi panel process to rate potential indicators, which were identified from the literature and national cardiovascular organizations. The top-rated indicators were pilot tested to determine their measurement feasibility with the use of data routinely collected in the Canadian health care system.

Results: A set of 28 indicators of primary prevention performance were identified, which were grouped into 5 domains: risk factor prevalence, screening, management, intermediate outcomes and long-term outcomes. The indicators reflect the major cardiovascular risk factors including smoking, obesity, hypertension, diabetes, dyslipidemia and atrial fibrillation. All indicators were determined to be amenable to measurement with the use of population-based administrative (physician claims, hospital admission, laboratory, medication), survey or electronic medical record databases.

Interpretation: The Cardiovascular Health in Ambulatory Care Research Team indicators of primary prevention performance provide a framework for the measurement of cardiovascular primary prevention efforts in Canada. The indicators may be used by clinicians, researchers and policy-makers interested in measuring and improving the prevention of cardiovascular disease in ambulatory care settings.

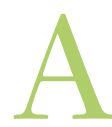

reduction in cardiovascular disease risk can be achieved through high-quality preventive care in the primary care setting. Although evidence-based interventions exist for the major cardiac risk factors, studies have shown that these interventions are underused in routine clinical practice, resulting in suboptimal risk factor control. ${ }^{1-3}$ The Cardiovascular Health in Ambulatory Care Research Team (CANHEART) initiative was established to improve the cardiovascular health of Canadians and to measure and improve the quality of cardiovascular preventive care in the ambulatory setting. ${ }^{4}$ A core research objective was to develop a set of indicators of primary prevention performance that were aligned with Canadian clinical practice guidelines, could be measured with the use of population-

Competing interests: None declared.

This article has been peer reviewed.

Correspondence to: Jack Tu, tu@ices.on.ca

CMAJ Open 2017. DOI:10.9778/cmajo.20160139 
based health databases and could serve as a foundation for future quality-improvement initiatives.

The Canadian Institute for Health Information and Health Quality Ontario have identified sets of primary care indicators; however, many are not currently measurable in Canada owing to limited data availability and are not specific to cardiovascular disease.$^{5-7}$ Furthermore, most sets of indicators of cardiovascular care developed in Canada and elsewhere focus on the hospital setting and on treatment of patients with established cardiovascular disease. ${ }^{8-12}$ Far less attention has been focused on improving performance in ambulatory cardiovascular care and preventing cardiovascular events, for which over 350000 Canadians were admitted to hospital in $2011,{ }^{13}$ with increasing numbers expected owing to the aging population. ${ }^{14}$ Past indicator sets include indicators that cannot be measured with the use of readily available population-based data sources, rely heavily on data abstracted from patient charts ${ }^{15}$ or were developed according to clinical guidelines in other countries. ${ }^{16} \mathrm{We}$ set out to develop a set of Canadian performance indicators focused on primary prevention of cardiovascular disease in the ambulatory care setting that could be measured with the use of routinely available data and that would be useful to clinicians and/or health system managers for identifying opportunities for care improvement.

\section{Methods}

\section{Recruitment of expert panel and external experts}

We established a multidisciplinary expert panel in 2012 to develop a set of indicators as a foundation for assessing performance in ambulatory cardiovascular preventive care. We invited Canadian academic experts in cardiovascular disease prevention who were knowledgeable about evidence-based cardiovascular preventive practices and had an understanding of the Canadian health databases required to measure potential indicators.

The panel consisted of 14 members with varied expertise to reflect the multidisciplinary nature of ambulatory cardiovascular care: 2 family physicians (S.J., K.T.), 4 cardiologists (D.L., D.K., R.S.B., P.L.) and 1 each of nephrologist (S.T.), geriatrician (A.B.), emergency physician (C.A.), endocrinologist (G.B.), respirologist (A.G.), stroke evaluation consultant (R.H.) and methodologist (C.S.). The CANHEART principal investigator (J.T.) served as the indicator panel chair. For the first round of indicator ratings, we also invited family physicians, specialist physicians and methodologists with expertise in quality indicator development to participate as external experts.

\section{Target patient population}

The target population for the CANHEART performance indicators consisted of adults aged 20 years or more with no history of cardiovascular disease (i.e., primary prevention patients). An upper age limit was not chosen, although it is recognized that patients aged 80 years or more form a heterogeneous group, with some near the end of life, in whom prevention is not indicated.

\section{Review of existing indicators}

Figure 1 summarizes the indicator selection process. In fall 2012, a medical librarian performed a literature search of the MEDLINE (1996-2012), Embase (1980-2012), Cochrane Database of Systematic Reviews (2005-2012) and HealthSTAR (1966-2012) databases to identify relevant ambulatory cardiovascular care indicators, performance measures and clinical practice guidelines. Key search terms included "cardiovascular diseases," "quality indicators," "performance measure," "ambulatory care" and "benchmarking." We also searched the grey literature to identify quality indicators and practice guidelines developed by leading organizations in Canada and the United States, including the American Heart Association/American College of Cardiology Foundation, Canadian Cardiovascular Society, Canadian Institute for Health Information, Canadian Stroke Strategy and Health Quality Ontario. Bibliographies of relevant articles and reports were hand-searched. We updated the literature search in 2016, searching MEDLINE using the keywords noted above to identify additional relevant manuscripts or guidelines published since the initial search.

\section{Indicator development}

We developed indicators using a 2-stage modified Delphi process $^{17}$ and the Canadian Cardiovascular Society's Best Practices for Quality Indicator Development. ${ }^{18} \mathrm{~A}$ key criterion was that indicators be measurable with the use of population-based health databases currently available in Canada, such as health administrative databases (e.g., physician claims, hospital admission, laboratory, medication), survey data (e.g., Canadian Community Health Survey) and electronic medical record databases. Where possible, indicators were harmonized with Canadian clinical practice guidelines endorsed by both a national specialty organization (e.g., Canadian Cardiovascular Society, Canadian Diabetes Association) and the Canadian Cardiovascular Harmonized National Guidelines Endeavour (C-CHANGE) Initiative, a national effort to harmonize guidelines for cardiovascular disease prevention in primary care. ${ }^{19,20}$ The panel endeavoured to include indicators for which care processes leading to improved patient outcomes have been shown in clinical trials.

In the first round of indicator ratings (late 2012/early 2013), the panellists and 7 external experts were emailed a list of 109 potential performance indicators (13 population health and 96 health care services) identified from the literature review, with draft definitions of each indicator's numerator, denominator, data source for measurement and source document (Appendix 1, available at www.cmajopen.ca/content/5/2/ E315/suppl/DC1). Panellists/external experts were asked to rate the indicators using the Canadian Cardiovascular Society Quality Indicator Rating Scale, a 7-point Likert scale (from 1 ["strongly disagree"] to 7 ["strongly agree"]) comprising individual ratings for 4 attributes: importance, scientific acceptability, feasibility and overall. ${ }^{18}$ The response rate was $90 \%$.

In a second-round in-person meeting of panel members (early 2013), mean ratings for each indicator were presented along with the detailed indicator definitions and issues noted by panellists. The importance and feasibility of measuring 
each indicator in the context of the provincial health care system was discussed, and panellists could suggest alternative indicators. Panellists then rerated each indicator $(100 \%$ response rate). Of 96 potential indicators, 75 with a mean overall score of 5.0 or higher were retained. Among these, several population health indicators (e.g., prevalence of diabetes, prevalence of smoking) were automatically retained as important measures of baseline population health amenable to population health and clinical interventions. Subsequently, a summary document was circulated to the panel and a teleconference held to discuss the second-round rating results. At this stage, in an effort to reduce the number of indicators chosen to a manageable set, it was decided to focus the initiative exclusively on primary prevention, thus eliminating secondary prevention indicators from further consideration $(n=$ 12). This left 63 indicators for pilot testing.

\section{Pilot testing}

We pilot tested measurement feasibility of the indicators using a cohort of 9.4 million adult primary prevention patients in Ontario from the CANHEART "big data" initiative, created through linkage of multiple population-based databases including the Canadian Institute for Health Information Discharge Abstract Database, the Ontario Health Insurance Plan database, the Electronic Medical Record Administrative Data Linked Database, the Dynacare Medical Laboratory database and other databases available at the Institute for Clinical Evaluative Sciences. ${ }^{4}$ These databases were chosen because they contained the data necessary to measure 1 or more indicators.

Extensive pilot testing occurred from 2014 to early 2016 and included defining and refining indicator numerator, denominator and exclusion criteria, and modifying these as appropriate based on preliminary results across patient groups

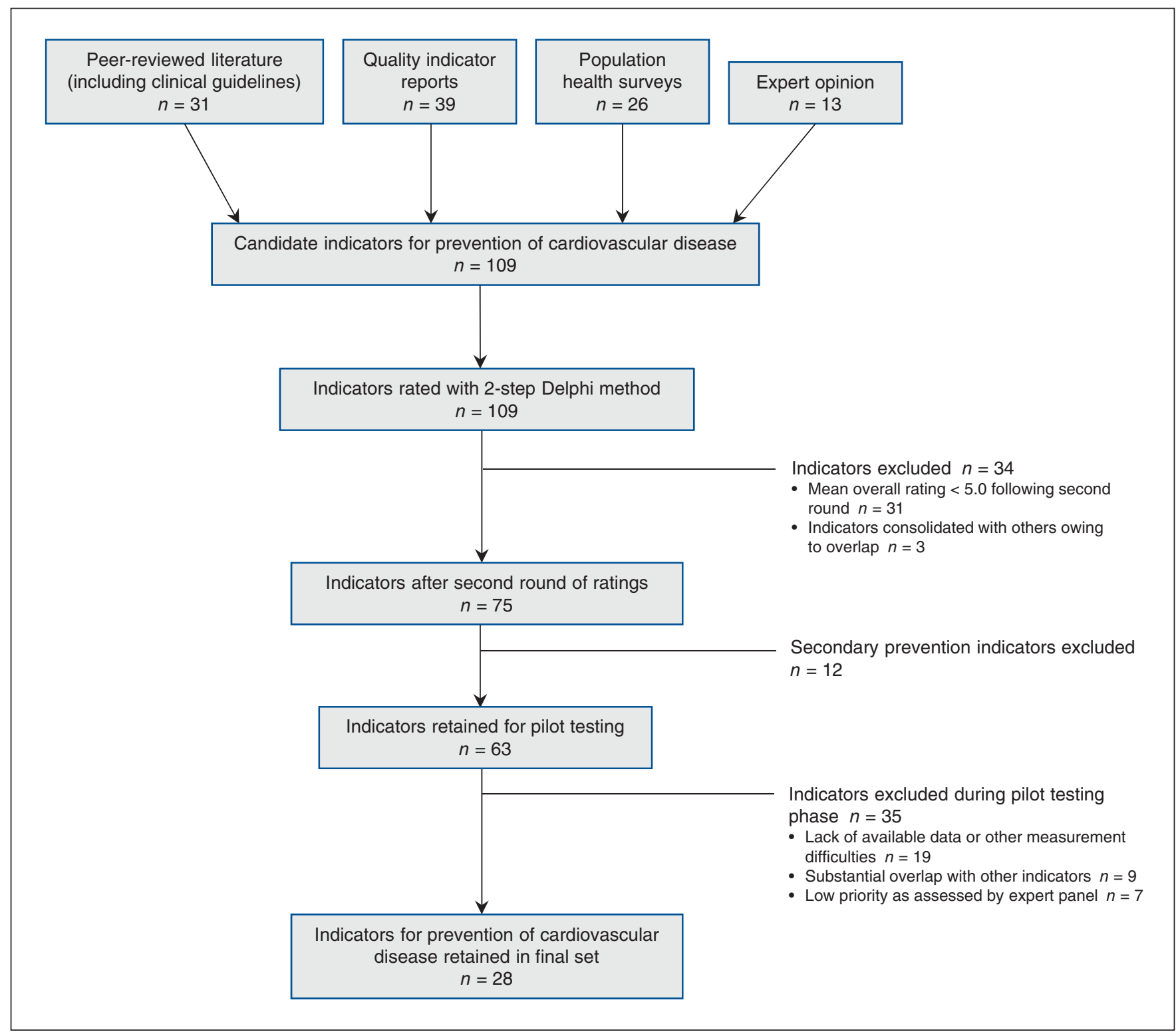

Figure 1: Flow chart of CANHEART primary prevention performance indicator selection process. 


\section{OPEN}

Research

and geographical regions. Pilot testing showed the data quality and the feasibility of using these data sources in Ontario to calculate the indicators. ${ }^{21}$ Furthermore, many of the indicators were shown to be associated with cardiovascular disease outcomes. ${ }^{21} \mathrm{We}$ excluded indicators that could not be measured because of lack of available data or other measurement difficulties $(n=19)$, that showed substantial overlap with other indicators $(n=9)$ or that were deemed low priority $(n=7)$.

\section{Ethics approval}

The study was approved by the Sunnybrook Health Sciences Centre Research Ethics Board.

\section{Results}

A total of 28 indicators characterizing many of the most important aspects of cardiovascular disease prevention in Canada were selected for the final set of CANHEART indicators of primary prevention performance. Indicators were grouped into 5 domains: prevalence, screening, management, interme- diate outcomes and long-term clinical outcomes (Table 1, Table 2). These domains were chosen to align with the practices involved in monitoring population health and primary care provision. Subject areas included the cardiac risk factors (smoking, obesity, hypertension, diabetes, dyslipidemia and atrial fibrillation) as well as access to primary care, since availability of primary care is a necessary intermediary of other measures of primary care performance. Appendix 2 (available at www.cmajopen.ca/content/5/2/E315/suppl/DC1) provides detailed information on guidelines and evidence supporting the use of each indicator, suggested data sources, and numerator and denominator definitions. Data on the performance of Ontario health regions on most of these indicators is available on the study Web site (www.canheart.ca/eAtlas).

\section{Indicators of risk factor prevalence}

The prevalence of traditional cardiovascular risk factors was included in the final set of performance measures because the panel felt that measures of a population's cardiovascular health could be influenced by both population health and

\begin{tabular}{|c|c|c|c|c|c|c|c|}
\hline \multirow[b]{2}{*}{ Domain } & \multicolumn{7}{|c|}{ Subject area; indicator } \\
\hline & Smoking & Obesity & Hypertension & Diabetes & Dyslipidemia & Atrial fibrillation & $\begin{array}{l}\text { Access to } \\
\text { primary care }\end{array}$ \\
\hline Prevalence & $\begin{array}{l}\text { Prevalence of } \\
\text { smoking }\end{array}$ & $\begin{array}{l}\text { Prevalence of } \\
\text { obesity }\end{array}$ & Prevalence of hypertension & $\begin{array}{l}\text { Prevalence of } \\
\text { diabetes }\end{array}$ & $\begin{array}{l}\text { Prevalence of high } \\
\text { lipid levels (e.g., } \\
\text { total cholesterol } \\
\geq 5.2 \mathrm{mmol} / \mathrm{L})\end{array}$ & $\begin{array}{l}\text { Prevalence of } \\
\text { atrial fibrillation }\end{array}$ & $\begin{array}{l}\% \text { of patients } \\
\text { who have } \\
\text { visited a } \\
\text { primary care } \\
\text { provider }\end{array}$ \\
\hline Screening & NA & $\begin{array}{l}\% \text { of patients } \\
\text { with height } \\
\text { and weight } \\
\text { measured }\end{array}$ & $\begin{array}{l}\% \text { of patients with blood } \\
\text { pressure measured }\end{array}$ & $\begin{array}{l}\% \text { of patients aged } \\
\geq 40 \text { yr who have had } \\
\text { full fasting blood } \\
\text { glucose or } \mathrm{HbA}_{1 \mathrm{c}} \\
\text { screening test in } \\
\text { previous } 36 \mathrm{mo}\end{array}$ & $\begin{array}{l}\% \text { of men aged } \\
\geq 40 \mathrm{yr} \text { and women } \\
\text { aged } \geq 50 \mathrm{yr} \text { who } \\
\text { have had full lipid } \\
\text { profile in previous } \\
5 \mathrm{yr}\end{array}$ & NA & NA \\
\hline Management & $\begin{array}{l}\% \text { of smokers } \\
\text { who received } \\
\text { smoking } \\
\text { cessation } \\
\text { counselling }\end{array}$ & NA & $\begin{array}{l}\% \text { of patients with } \\
\text { hypertension taking } \\
\geq 1 \text { antihypertensive } \\
\text { medication } \\
\text { OR } \\
\text { Mean number of } \\
\text { antihypertensive } \\
\text { medications taken among } \\
\text { patients with treated } \\
\text { hypertension }\end{array}$ & $\begin{array}{l}\text { 1. \% of patients with } \\
\text { diabetes taking } \\
\text { antidiabetic } \\
\text { medications } \\
2 . \% \text { of patients with } \\
\text { diabetes aged } \geq 55 \mathrm{yr} \\
\text { taking ACE inhibitors/ } \\
\text { ARBs } \\
3 . \% \text { of patients with } \\
\text { diabetes aged } \geq 40 \mathrm{yr} \\
\text { taking statins }\end{array}$ & $\begin{array}{l}\% \text { of primary } \\
\text { prevention patients } \\
\text { at high risk (e.g., } \\
\text { LDL-C level > 5.0, } \\
\text { high Framingham } \\
\text { risk score, diabetic) } \\
\text { taking statins }\end{array}$ & $\begin{array}{l}\% \text { of patients } \\
\text { with atrial } \\
\text { fibrillation } \\
\text { taking warfarin } \\
\text { or direct oral } \\
\text { anticoagulants }\end{array}$ & $\begin{array}{l}\text { Mean no. of } \\
\text { primary care } \\
\text { visits per yr } \\
\text { (e.g., for } \\
\text { hypertension, } \\
\text { diabetes) }\end{array}$ \\
\hline $\begin{array}{l}\text { Intermediate } \\
\text { outcomes }\end{array}$ & NA & NA & $\begin{array}{l}\% \text { of patients with } \\
\text { hypertension with measured } \\
\text { blood pressure control } \\
(<140 \mathrm{~mm} \mathrm{Hg} \text { systolic and } \\
<90 \mathrm{~mm} \mathrm{Hg} \text { diastolic })^{\star} \\
\text { OR } \\
\text { Rate of emergency } \\
\text { department visits for } \\
\text { hypertension among } \\
\text { patients with hypertension }\end{array}$ & $\begin{array}{l}\% \text { of patients with } \\
\text { diabetes with } \mathrm{HbA}_{1 \mathrm{c}} \\
\text { level controlled } \\
(\leq 7 \%) \dagger\end{array}$ & $\begin{array}{l}\% \text { of patients } \\
\text { taking statins for } \\
\text { primary prevention } \\
\text { who have lipid } \\
\text { levels controlled } \\
\text { (LDL-C } \\
\leq 2.0 \mathrm{mmol} / \mathrm{L})\end{array}$ & $\begin{array}{l}\% \text { of time in } \\
\text { therapeutic } \\
\text { range (INR } \\
2-3 \text { ) among } \\
\text { patients with } \\
\text { atrial fibrillation } \\
\text { taking warfarin }\end{array}$ & NA \\
\hline
\end{tabular}




\section{Table 2: CANHEART indicators of long-term outcomes*}

Rate of acute myocardial infarction

Rate of stroke (ischemic/hemorrhagic)

Rate of congestive heart failure (requiring hospital admission)

Rate of revascularization (PCI/CABG)

Cardiovascular and/or all-cause mortality

Note: $\mathrm{CABG}=$ coronary artery bypass grafting, $\mathrm{PCl}=$ percutaneous coronary intervention.

${ }^{*}$ Age-adjusted and/or age- and sex-stratified rates per 1000 person- years measured over at least 3 years.

clinical interventions, although it was recognized that this may largely be outside the direct control of a primary care provider. Several of the prevalence indicators are routinely measured in Statistics Canada's Canadian Community Health Survey, which permits trend analysis and estimates at the health region level across Canada. ${ }^{24}$ The prevalence of conditions such as hypertension and diabetes can also be measured with the use of validated health administrative chronic disease algorithms or electronic medical record databases. ${ }^{25}$ An indicator reflecting the proportion of the population who visited a primary care provider was also included, as accessing primary care is a precondition for lowering cardiovascular disease risk through health care system interventions. ${ }^{26}$

\section{Indicators of risk factor screening}

Screening for modifiable cardiac risk factors, specifically obesity, hypertension, diabetes and dyslipidemia, is recommended by Canadian and international practice guidelines ${ }^{27-32}$ and was highly rated by the panel for its importance in identifying people who would benefit from behavioural modification counselling and/or medical intervention. In addition to being universally accepted contributors to cardiovascular disease, the risk factors selected for screening are also common, and their management is supported by scientific evidence. Furthermore, rates of screening for diabetes and dyslipidemia can be obtained from physician or laboratory claims databases, ${ }^{33}$ and those of screening for obesity and hypertension from electronic medical record databases.

\section{Indicators of risk factor management}

To capture aspects of performance in primary prevention of cardiovascular disease among the population with cardiovascular disease risk factors, 8 indicators of risk factor management were included. For smoking, the proportion of smokers who received smoking cessation counselling was selected, and the proportion of patients receiving drug-based treatment was chosen for hypertension, diabetes, dyslipidemia and atrial fibrillation. Drug treatment rates for people with diagnosed risk factors for cardiovascular disease can be measured with the use of electronic medical record databases or through linkage of drug claims databases with health administrative databases. Since risk factor management by family physicians usually requires multiple primary care visits, the panel also recommended measurement of the annual number of primary care visits.

\section{Indicators of intermediate outcomes}

Similar to risk factor management, the panel recognized the value of indicators of risk factor control (termed intermediate outcomes) in reducing cardiovascular disease risk and recommended 4 indicators in this domain: the proportion of patients with hypertension with controlled blood pressure, the proportion of patients with diabetes with controlled blood glucose levels, the proportion of statin users with controlled lipid levels and the percentage of time in therapeutic range for patients with atrial fibrillation taking warfarin (Table 1). However, it was recognized that not all patients want or require aggressive treatment, and the control targets may not be suitable for all patients. These indicators can be measured through linkage of health administrative, drug claim, electronic medical record and laboratory databases.

\section{Indicators of long-term outcomes}

To determine the impact of efforts to prevent cardiovascular disease in the ambulatory care setting, the panel recommended assessment of long-term clinical outcomes including rates of death from cardiovascular disease and/or all-cause mortality rates (Table 2). Although measuring cardiovascular mortality is preferred, all-cause mortality can be an alternative when access to cause of death information is difficult, since many cardiovascular treatments have been shown to reduce all-cause mortality. Data for these measures are routinely available from hospital discharge abstract and vital statistics databases (recommended International Classification of Diseases, 9th and 10th revisions codes are reported elsewhere ${ }^{4}$ ). The panel refrained from specifying time periods for most indicators because the choice will vary with the clinical context, availability of data and local needs of users.

\section{Interpretation}

The CANHEART Primary Prevention Indicator Panel identified 28 indicators to evaluate key elements in performance of the prevention and management of cardiovascular disease risk in the primary care setting. The American Heart Association has identified a set of primary prevention performance measures; ${ }^{16}$ however, their focus is on process-of-care indicators, whereas the CANHEART set encompasses the health care system continuum, from population health to care delivery processes to outcomes.

The CANHEART indicators are not meant to form an exhaustive list but, rather, cover many important aspects of primary cardiovascular care that can be measured with the use of data sources likely to be available across Canada. The indicators are relevant to multiple stakeholders, including patients, primary care providers, policy-makers and public health organizations, and may be used in system-wide public reporting efforts and/or to facilitate quality-improvement initiatives.

Charting progress in the prevalence, management, control and outcomes of cardiovascular risk factors over time, across 
regions and among subpopulations at high risk (e.g., South Asians, Indigenous peoples) can also enable evaluation of the impact of policies aimed at improving the quality of primary cardiovascular care and identify potential deficiencies or inequities in care requiring targeted action. It is hoped that a common core set of indicators will lead to better documentation and methods of measurement such as stimulating collaboration with electronic medical record vendors to develop standard indicator collection methods in their systems, which have often been inconsistent in methods of data capture.

\section{Limitations}

Although the panel sought to include the most important aspects of cardiovascular primary prevention in the final indicator set, some relevant measures, such as those related to diet and physical activity, patient safety and satisfaction, unnecessary testing and care coordination, were not included owing to limitations in data availability at the population level, uncertainties in their association with patient outcomes or challenges in defining such indicators. However, we plan to update the indicator list and definitions as new data sources and clinical studies become available. In addition, as some patients may not be suitable candidates for some indicators (e.g., because of medication allergies, comorbidities, patient preferences, choosing lifestyle modifications over medications), benchmark rates may not be $100 \%$ and could vary by population. Nevertheless, we believe that measurement of these indicators is an important first step. Future work could focus on identifying realistic benchmarks for each indicator. Performance on certain indicators may also reflect complex community-level factors outside the health care system (e.g., smoking bylaws, built environment) or outside the control of health care providers (e.g., socioeconomic status, ethnicity).

\section{Conclusion}

Cardiovascular disease prevention in Canada has the potential to improve the quality of life of many Canadians and reduce the overall burden of cardiovascular disease on the Canadian health care system as the population ages. Historically, performance in cardiovascular disease prevention in Canada has been difficult to assess. The CANHEART primary prevention indicators have been created to address this knowledge gap, providing a means to evaluate cardiovascular-related ambulatory care and identify target areas for improvement in performance in the health care system in Canada and elsewhere.

\section{References}

1. Braga M, Casanova A, Teoh H, et al.; Diabetes Registry to Improve Vascular Events (DRIVE) Investigators. Treatment gaps in the management of cardiovascular risk factors in patients with type 2 diabetes in Canada. Can $\mathcal{7}$ Cardiol 2010;26:297-302

2. Hennessy DA, Tanuseputro P, Tuna M, et al. Population health impact of statin treatment in Canada. Health Rep 2016;27:20-8.

3. Joffres MR, Hamet P, MacLean DR, et al. Distribution of blood pressure and hypertension in Canada and the United States. Am f Hypertens 2001;14:1099-105.

4. Tu JV, Chu A, Donovan LR, et al. The Cardiovascular Health in Ambulatory Care Research Team (CANHEART): using big data to measure and improve cardiovascular health and healthcare services. Circ Cardiovasc Qual Outcomes 2015;8:204-12.

5. Pan-Canadian primary healthcare indicators, Report 1, Volume 1. Ottawa: Canadian Institute for Health Information; 2006
6. Pan-Canadian primary bealthcare indicators, Report 1, Volume 2. Ottawa: Canadian Institute for Health Information; 2006.

7. A primary care performance measurement framework for Ontario - report of the Steering Committee for the Ontario Primary Care Performance Measurement Initiative: phase one. Toronto: Health Quality Ontario; 2014.

8. Tu JV, Khalid L, Donovan LR, et al.; Canadian Cardiovascular Outcomes Research Team/Canadian Cardiovascular Society Acute Myocardial Infarction Quality Indicator Panel. Indicators of quality of care for patients with acute myocardial infarction. CMA7 2008;179:909-15.

9. Lee DS, Tran C, Flintoft V, et al.; Canadian Cardiovascular Outcomes Research Team/Canadian Cardiovascular Society Heart Failure Quality Indicator Panel. CCORT/CCS quality indicators for congestive heart failure care. Can 7 Cardiol 2003;19:357-64.

10. Levine GN, Bates ER, Blankenship JC, et al. 2015 ACC/AHA/SCAI Focused Update on Primary Percutaneous Coronary Intervention for Patients with ST-Elevation Myocardial Infarction: an update of the 2011 ACCF/AHA/ SCAI Guideline for Percutaneous Coronary Intervention and the 2013 ACCF/AHA Guideline for the Management of ST-Elevation Myocardial Infarction: a report of the American College of Cardiology/American Heart Association Task Force on Clinical Practice Guidelines and the Society for Cardiovascular Angiography and Interventions [published erratum in Circulation 2016;133:e442-3]. Circulation 2016;133:1135-47.

11. Lambie L, Mattke S; Members of the OECD Cardiac Care Panel. Selecting indicators for the quality of cardiac care at the health systems level in OECD countries. Paris: Organisation for Economic Co-operation and Development; 2004

12. Tu JV, Donovan LR, Lee DS. Effectiveness of public report cards for improving the quality of cardiac care: the effect study: a randomized trial. $7 A M A$ 2009;302:2330-7.

13. Transforming recovery. Ottawa: Heart and Stroke Foundation; 2017. Available: www.heartandstroke.ca/what-we-do/our-impact/transforming-recovery (accessed 2017 Apr. 19).

14. Rawson NS, Chu R, Ismaila AS, et al. The aging Canadian population and hospitalizations for acute myocardial infarction: projection to 2020. BMC Cardiovasc Disord 2012;12:25.

15. Burge FI, Bower K, Putnam W, et al. Quality indicators for cardiovascular primary care. Can 7 Cardiol 2007;23:383-8.

16. Redberg RF, Benjamin EJ, Bittner V, et al.; American Academy of Family Physicians; American Association of Cardiovascular and Pulmonary Rehabilitation; Preventive Cardiovascular Nurses Association. ACCF/AHA 2009 performance measures for primary prevention of cardiovascular disease in adults: a report of the American College of Cardiology Foundation/American Heart Association Task Force on Performance Measures (Writing Committee to Develop Performance Measures for Primary Prevention of Cardiovascular Disease) developed in collaboration with the American Academy of Family Physicians; American Association of Cardiovascular and Pulmonary Rehabilitation; and Preventive Cardiovascular Nurses Association: endorsed by the American College of Preventive Medicine, American College of Sports Medicine, and Society for Women's Health Research. 7 Am Coll Cardiol 2009;54: 1364-405.

17. Fink A, Kosecoff J, Chassin M, et al. Consensus methods: characteristics and guidelines for use. Am 7 Public Health 1984;74:979-83.

18. Tu JV, Abrahamyan L, Donovan LR, et al.; Canadian Cardiovascular Society Quality Indicators Steering Committee. Best practices for developing cardiovascular quality indicators. Can 7 Cardiol 2013;29:1516-9.

19. Tobe SW, Stone JA, Brouwers M, et al. Harmonization of guidelines for the prevention and treatment of cardiovascular disease: the C-CHANGE Initiative. CMAf 2011;183:E1135-50.

20. Tobe SW, Stone JA, Walker KM, et al. Canadian Cardiovascular Harmonized National Guidelines Endeavour (C-CHANGE): 2014 update. CMAf 2014;186:1299-305.

21. Tu JV, Chu A, Maclagan LC, et al.; Cardiovascular Health in Ambulatory Care Research Team (CANHEART). Regional variations in ambulatory care and incidence of cardiovascular events. CMA7 2017;189:E494-501.

22. Dasgupta K, Quinn RR, Zarnke KB, et al.; Canadian Hypertension Education Program. The 2014 Canadian Hypertension Education Program recommendations for blood pressure measurement, diagnosis, assessment of risk, prevention, and treatment of hypertension. Can 7 Cardiol 2014;30:485-501.

23. Imran SA, Rabasa-Lhoret R, Ross S; Canadian Diabetes Association Clinical Practice Guidelines Expert Committee. Targets for glycemic control. Can 7 Diabetes 2013;37(Suppl 1):S31-4.

24. Canadian Community Health Survey - annual component. Ottawa: Statistics Canada; 2016

25. Williamson T, Green ME, Birtwhistle R, et al. Validating the 8 CPCSSN case definitions for chronic disease surveillance in a primary care database of electronic health records. Ann Fam Med 2014;12:367-72.

26. Starfield B, Shi L, Macinko J. Contribution of primary care to health systems and health. Milbank Q 2005;83:457-502.

27. Anderson TJ, Grégoire J, Hegele RA, et al. 2012 update of the Canadian Cardiovascular Society guidelines for the diagnosis and treatment of dyslipidemia for the prevention of cardiovascular disease in the adult. Can 7 Cardiol 2013;29:151-67. 
28. Cheng AY, Lau DC. The Canadian Diabetes Association 2013 clinical practice guidelines - raising the bar and setting higher standards! Can 7 Diabetes 2013;37:137-8

29. Lau DC, Douketis JD, Morrison KM, et al.; Obesity Canada Clinical Practice Guidelines Expert Panel. 2006 Canadian clinical practice guidelines on the management and prevention of obesity in adults and children [summary]. CMAf 2007;176:S1-13.

30. Leung AA, Nerenberg K, Daskalopoulou SS, et al.; CHEP Guidelines Task Force. Hypertension Canada's 2016 Canadian Hypertension Education Program guidelines for blood pressure measurement, diagnosis, assessment of risk, prevention, and treatment of hypertension. Can 7 Cardiol 2016;32: 569-88.

31. Lindsay P, Connor Gorber S, Joffres M, et al.; Canadian Task Force on Preventive Health Care (CTFPHC). Recommendations on screening for high blood pressure in Canadian adults. Can Fam Physician 2013;59:927-33, e393-400

32. U.S. Preventive Services Task Force. Screening for high blood pressure: U.S. Preventive Services Task Force reaffirmation recommendation statement. Ann Intern Med 2007;147:783-6.

33. Borkhoff CM, Saskin R, Rabeneck L, et al. Disparities in receipt of screening tests for cancer, diabetes and high cholesterol in Ontario, Canada: a population-based study using area-based methods. Can 7 Public Health 2013;104: e284-90

Affiliations: Institute for Clinical Evaluative Sciences (J. Tu, Maclagan, Ko, Atzema, Booth, K. Tu, Lee, Hall, Bhatia, Gershon, Chu); Schulich Heart Centre (J. Tu, Ko), Division of Emergency Medicine (Atzema), and Division of Nephrology (Tobe), Sunnybrook Health Sciences Centre; University of Toronto (J. Tu, Ko, Atzema, Booth, K. Tu, Lee, Bierman, Hall, Bhatia, Gershon, Tobe, Liu, Chu); St. Michael's Hospital (Booth), Toronto, Ont.; Bruyère Research Institute (Johnston); University of Ottawa (Johnston), Ottawa, Ont.; University Health Network (K. Tu, Lee, Bhatia), Toronto, Ont.; Center for Evidence and Practice Improvement (Bierman), Agency for Healthcare Research and Quality, Rockville, MD; Women's College Hospital Institute for Health Systems Solutions and Virtual Care (Bhatia), Toronto, Ont.; Northern Ontario School of Medicine (Tobe), Sudbury, Ont.; University of Ottawa Heart Institute (Liu); Statistics Canada (Sanmartin), Ottawa, Ont.

Contributors: Jack Tu conceived of the study and Laura Maclagan analyzed the data. Jack Tu and Laura Maclagan drafted the manuscript, and Dennis Ko, Clare Atzema, Gillian Booth, Sharon Johnston, Karen Tu,
Douglas Lee, Arlene Bierman, Ruth Hall, R. Sacha Bhatia, Andrea Gershon, Sheldon Tobe, Claudia Sanmartin, Peter Liu and Anna Chu critically reviewed it. All of the authors contributed to the study design and data interpretation, approved the final version to be published and agreed to act as guarantors of the work.

Funding: The CANHEART initiative is funded through a Chronic Diseases Team Grant (no. TCA 118349) from the Institute of Circulatory and Respiratory Health, Canadian Institutes of Health Research (CIHR), a CIHR Foundation grant (no. FDN-143313) and a Canadian Vascular Network (CVN) seed grant. The CVN is funded by the CIHR in partnership with Hypertension Canada. This study was supported by the Institute for Clinical Evaluative Sciences, which is funded by annual grants from the Ontario Ministry of Health and Long-Term Care. Jack Tu is supported by a Tier 1 Canada Research Chair in Health Services Research and an Eaton Family Scholar award. Dennis Ko, Gillian Booth and Douglas Lee are supported by Career Investigator Awards and Clare Atzema is supported by a New Investigator Award from the Heart and Stoke Foundation. Douglas Lee is also the Ted Rogers Chair in Heart Function Outcomes. Andrea Gershon is supported by a Physicians' Services Incorporated Fellowship in translational research. Karen Tu is supported by a Research Scholar award from the Department of Family and Community Medicine at the University of Toronto. Sheldon Tobe is supported by the Heart and Stroke Foundation and the Northern Ontario School of Medicine's Research Chair in Aboriginal and Rural Health Research.

Disclaimer: The opinions, results and conclusions expressed herein are those of the authors and are independent from the Institute for Clinical Evaluative Sciences (ICES) and the funding sources. No endorsement by the ICES, the Ontario Ministry of Health and Long-Term Care, the Canadian Vascular Network or the Canadian Institutes of Health Research is intended or should be inferred. This article was conducted as an outside activity. No official endorsement by the Agency for Healthcare Research and Quality, the US Department of Health and Human Services or the US federal government is intended or inferred.

Supplemental information: For reviewer comments and the original submission of this manuscript, please see www.cmajopen.ca/content/5/2/ E315/suppl/DC1 